\title{
Reconfiguring Sociomateriality from a Neurobiological Perspective
}

\section{Lars Taxén}

Linköping University

lars.taxen@gmail.com

\section{Abstract}

The aim of this paper is to propose a reconfiguration of sociomateriality (SM) from a neurobiological perspective, which maintains the relational ontology of SM without relapsing into untenable entanglement positions of strong SM (SSM).

Keywords: Sociomateriality, Neurobiological perspective.

\section{Introduction}

The sociomaterial (SM) strand of research - or the predominantly 'strong' variant of SM (SSM) that drew on agential realism as its foundation (Barad, 2003) - was introduced in information systems (IS) by Orlikowski and Scott (2008). Notwithstanding the other variants of SM, such as 'weak' and SM based on critical realism sociomateriality, this paper focuses on the extant limitations of SSM and makes a case on how a neurobiological perspective can advance the SM strand of research in IS.

\section{Limitations of SSM}

Notwithstanding the general belief that SSM is "extremely theoretical" and therefore difficult to decipher (Leonardi, 2013), it is safe to say that the fundamental tenets of SSM suggests that SSM is purported to be generally applicable - that is to say, "there is no reason, in principle, why this genre [sociomateriality] of scholarship would not be appropriate for historical manifestations of work and organizations" (Orlikowski and Scott, 2008, p. 463). Indeed, the limitations of SM may be elucidated in a straightforward manner using the example of a cellist in concert (see Figure 1). This approach adheres to the thesis that "if something is understood well, it can be explained simply" (Paul, 2010, p. 380).
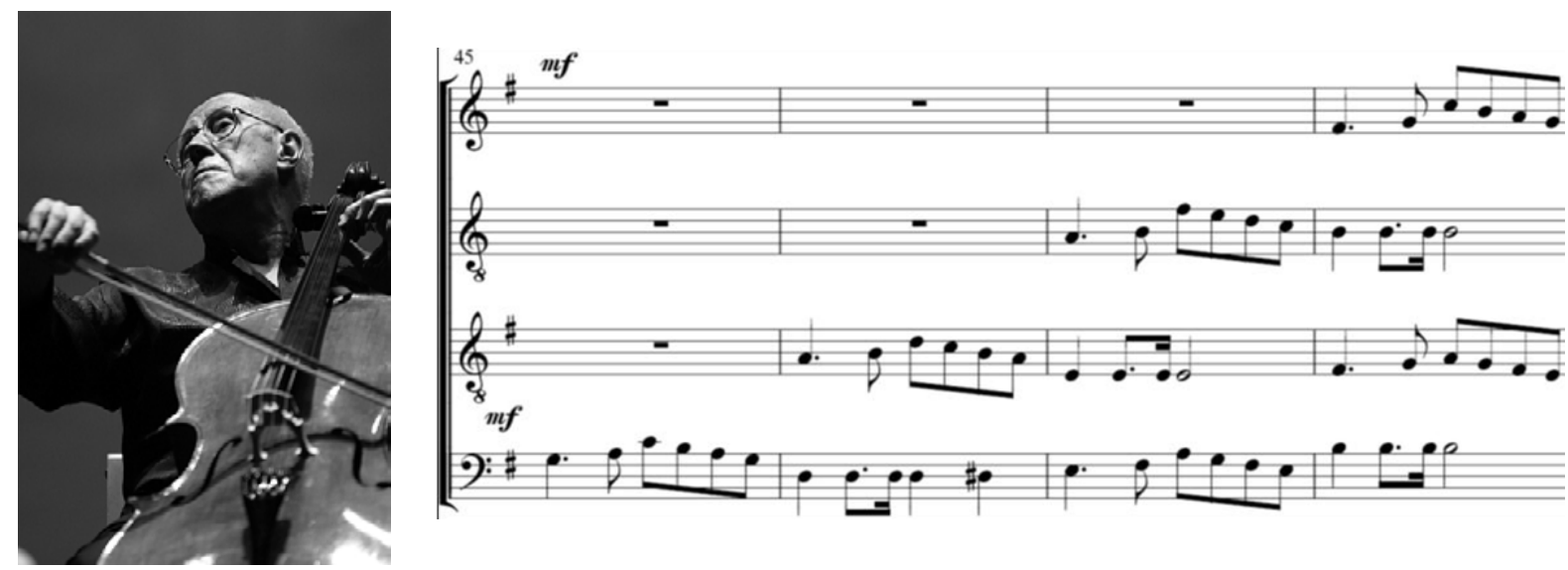

Figure 1 Mstislav Rostropovič in Concert Playing the Cello Voice in a Quartet

- $\quad$ SSM tenet "There are no stable pre-existing entities" (Hassan, 2016, p.17). Clearly, the musician, the score and the cello exist before the performance, and remain stable 
enough throughout the concert. Concerning pre-existence, the musician's playing skill, the instrument and several other activity-relevant entities need to be in place before the activity can be carried out.

- SSM tenet "[Entities] (whether humans or technologies) have no inherent properties, but acquire form, attributes, and capabilities through their interpenetration" (Orlikowski \& Scott, 2008, p. 455). Undoubtedly, the cellist and the cello have properties that exist before the concert. However, these may be modified by the activity-for example, the cellist's playing skill may be improved and the timbre of the cello may change.

- SSM tenet "[Any] distinction of humans and technologies is analytical only" (Orlikowski $\&$ Scott, 2008, p. 456). Certainly, most people have no problem in distinguishing Rostropovič from his cello. Thus, it seems bizarre to claim that this distinction is 'analytical only.' This tenet devaluates the role of the acting individual, which means that SSM is unable to elucidate uniquely human issues such as communication, meaning, interpretation, and action.

The example demonstrates a concrete, every-day situation that SSM is unable to illuminate. Therefore, if SM is to contribute to IS, further work is needed to reconfigure its tenets. This paper intends to contribute a solution for this reconfiguration, specifically from the neurobiological perspective.

\section{Neurobiological Reconfiguration for SM}

To address the limitations of SSM, a neurobiological point of departure is proposed. The main motivation for this position is to establish the 'individual' on par with the 'social' and 'material' in the SM discourse, and in doing so, providing a tripartite analysis ground for advancing SM: the individual, the social, the material. The proposal is based on the following foundational assumptions.

\subsection{A Dialectical Ontology}

The relatum between individual and sociomaterial is seen as dialectical, which means that relata are pairs of opposites. These opposites are different but mutually depending on and impacting each other (Israel, 1979) - e.g. a classic example is the relation between master-slave. In that sense, individuals cannot be understood without taking their social environment into account and vice versa. The individual (neural) and sociomaterial realms form a totality, which parts "cannot be separated or isolated without destroying the phenomenon that is studied" (Toomela, 2014, p. 337). In essence, the dialectical relation implies a specific way of conceiving parts and whole:

[The] ancient debate on emergence, whether indeed wholes may have properties not intrinsic to the parts, is beside the point. The fact is that the parts have properties that are characteristic of them only as they are parts of wholes; the properties come into existence in the interaction that makes the whole (Levins \& Lewontin, 1985, p. 273).

Consequently, the dialectical ontology complies with substantialist and process metaphysics since it comprises both being - that is, "what there is" - and becoming - that is, "what is occurring" (Cecez-Kecmanovic, 2016). 


\subsection{The Substantialist Aspect-The Relata}

Action requires that an infrastructure is in place before we can engage in any activity, including communication: There is "always something that exists first as a given, as an issue, as a problem" (Latour, 2009, p. 5). Such an infrastructure, which can be called as communal, comprises factors of three kinds: biological, social, and circumstantial (Harris, 1996).

Biological factors concern the physical and mental capacities of the human being. A fundamental biological assumption is that brains evolved to control the activities of bodies in the world. The "mental is inextricably interwoven with body, world and action, where the mind consists of structures that operate on the world via their role in determining action" (Love, 2004, p. 527). Biological factors derive from neurobiological capacities developed during the phylogenetic evolution of humankind. Such capacities, which every healthy human being is endowed with at birth, "are universal and inherent for all humans, independent of language and environmental conditions" (Kotik-Friedgut, 2006, p. 43).

Social factors are entities and practices that are relevant in a certain community. For example, the layout of score as in Figure 1 has evolved over long periods in various musical activities. This artefact makes sense only in musical communities, as do the cello, norms for playing, musical schools, etc.

Circumstantial factors pertain to the particularity of situations. In the musical example, the musician's playing skill is a biological factor, the layout of the musical score a social factor, and the presence of the player and his cello at the time of the concert a circumstantial factor.

\subsection{The Processual Aspect-Dialectics between Relata}

The processual aspect, which can be referred to as communalization, is seen as a dynamical systems process (Gibbs \& Cameron, 2008) 'anchored' by neural attractors in individual brains and communal attractors in communities. The neural anchoring implies that the individual is capable of preforming a multitude of potential actions, which are stabilized and constrained by communal anchoring, and thus considering "human action within its systemic anchoring" (Boesch, 1991, p. 17) (see Figure 2).

External stimuli, such as someone uttering the word "CAT" or the appearance of a cat (communal attractors), converge to the same neural attractor basin (e.g. "cat") in the neural phase space of the individual.

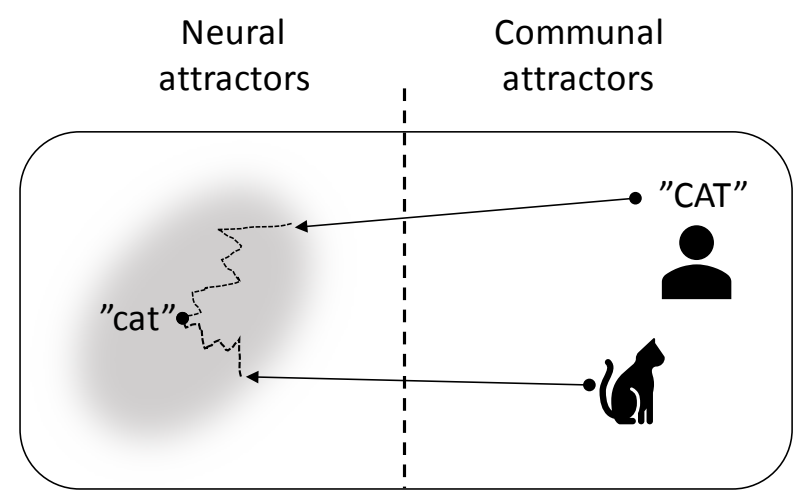

Figure 2 The dialectical relation anchored by neural and communal attractors

Since every action changes both biological and social factors, the communal infrastructure is always in becoming and only temporally stabilized, however on vastly different timescales 
ranging from millions of years (biological - evolutionary), cultural-historical time (communal), and millisecond (biological-neural).

The communalization process can be illustrated by the musical example. The dynamics involved in transforming Rostropovič into an outstanding cellist involves a long and arduous practicing with communal attractors such as the cello and the score. Eventually, neural and communal attractors converged into a unity so tightly intertwined that Rostropovič's playing become virtually effortless:

There no longer exist relations between us. Some time ago I lost my sense of the border between us.... I experience no difficulty in playing sounds.... The cello is my tool no more (Rostropovič, quoted in Zinchenko, 1996, p. 295).

Therefore, action, whether individual or joint (as in the quartet example in Figure 1), is from the outset social. Joint action is based on individual action and "constituted by the fitting together of the lines of behaviour of the separate participants" (Blumer, 1969, p. 70).

\section{Discussion}

Any theory, which purports to elucidate the relation between the social and material in IS theorizing, should be generally applicable and not limited to the IS field. As the musical example shows, this is not the case for SSM. The inevitable conclusion is that the extreme relational ontology of SSM is untenable as a foundation of the IS field. Alternative ways out of this dilemma are discussed below.

\subsection{Weak Sociomateriality}

The 'weak' variant of SM (WSM) rejects the "strong sociomaterialist claims that the existence of entities is wholly relational" (Jones, 2014, p. 918). Entities "exist independently of their enactment in practice, even while it is through relations between entities that agency can be explained" (Cecez-Kecmanovic et al., 2014, p.825).

WSM concurs with the dialectical approach in several aspects. For instance, WSM may accommodate "the pre-existence of social structure" (Jones, 2014, p. 919), which complies with the communal infrastructure. Another point of adherence concerns the dynamics, where WSM claims that "sociomaterial entanglement may, in principle, be open to revision at any instant" (Jones, 2014, p. 919). Moreover, WSM can be used for inquiries in practical settings. Nonetheless, WSM lacks a communicational theory and a clear conception of individuality.

\subsection{Imbrication}

The notion of 'imbrication' for conceptualizing the human-material interlocking aligns well with the dialectical approach. However, as Leonardi (2011) concedes: "Using the imagery of imbrices and tegulae has its problems. Both tiles are made of "material" in the sense that they are physical creations of clay. The struggle to find a suitable image with which to describe the imbrication of human and material agencies points to the conceptual difficulty of integrating these phenomena" (Leonardi, 2011, p. 151). This paper argues that the dialectical approach provides a solution to this dilemma, since one 'tile' is the neurobiology of the human being and another 'tile' the social conceived as communal attractors. 


\subsection{Further Development}

\subsubsection{Communication}

Communication can be accommodated in the dialectical approach using the Communication Theory of Integrational Linguistics (e.g., Harris, 1996) which suggests that any communicational act requires a communicational infrastructure comprising the same kinds of factors as the communal infrastructure.

\subsubsection{IS and Information Technology (IT) Artefacts}

IS becomes socialized in the dialectical approach as communalized IT artefacts, which means that the 'system' in IS conceptualization includes the individual. In that sense, the IT artefact becomes informative for the individual in communalization. Moreover, it remains an artefact, possibly modified, throughout communalization. Consequently, we "do not need to put humans inside the boundary of the IT artefact in order to make these artefacts social" (Goldkuhl, 2013, p. 94).

\subsubsection{Materiality}

The neurobiological point of departure implies that any external materiality, which our sensory system can perceive, may be communalized into a communal attractor, regardless of the particular physicality of sensations. The decisive point is whether that materiality signifies something relevant for individual or joint actions. To illustrate this point, consider the material basis of sheet music in Figure 1. Traditionally, this has been paper. Now, the paper is gradually replaced by digital sheet music presented on tablets. However, the layout of the sheet music remains the same, which indicates that its composition is highly efficient with respect to our neurobiological capacities for acting in musical communities.

\subsubsection{Practice}

SSM holds that categories are constituently entangled - that is, only locally and temporarily possible to separate and stabilize for analytical purposes through 'agential cuts' (Barad, 2003). However, how to perform this cut is problematic since categories are always indeterminate. This in turn aggravates the practical application of SSM. The dialectical approach, on the other hand, provides a distinct canvas for analysing and informing practice, where the individual, social and material are from the outset disentangled, although dynamically related.

\section{Conclusion}

The SSM relational ontology of agential realism is too extreme to be used as a basis for IS theorizing. Importantly, it is necessary to include substantialist elements without relapsing into the other extreme-that is, positivism. The dialectical approach is a potential solution to overcome those extreme positions. This requires the individual to be included as a prime constituent on the same par as the social and the material. The 'inseparability' of the social and material needs to be seen as an individual experience (as exemplified in the Rostropovič statement above). Concerning materiality, the SM tenet 'all materiality is social' needs to be reformulated as 'any form of materiality may become social', depending on whether it has undergone communalization or not. By reconstructing SM along the lines indicated, the ambition of SM to base IS theorizing on a relational ontology can be kept, while simultaneously providing a foundation that is generally applicable and thereby making it intelligible to practitioners. 


\section{References}

Barad, K. (2003). Posthumanist Performativity: Toward an Understanding of How Matter Comes to Matter. Signs, 28(3), 801-831. doi: https://doi.org/10.1086/345321

Blumer, H. (1969). Symbolic Interactionism: Perspective and Method. Englewood Cliffs, N.J.: Prentice-Hall.

Boesch, E. (1991). Symbolic Action Theory and Cultural Psychology. Berlin: Springer. doi: https://doi.org/10.1007/978-3-642-84497-3

Cecez-Kecmanovic, D., Galliers, R.D., Henfridsson, O., Newell, S., \& Vidgen R. (2014). The Sociomateriality of Information Systems: Current Status, Future Directions. MIS Quarterly, 38(3), 809-830. doi: https://doi.org/10.25300/MISQ/2014/38:3.3

Cecez-Kecmanovic, D. (2016). From Substantialist to Process Metaphysics - Exploring Shifts in IS Research. In Lucas Introna, Donncha Kavanagh, Séamas Kelly, Wanda Orlikowski, Susan Scott (Eds.) Beyond Interpretivism? New Encounters with Technology and Organization (pp. 35-57). IFIP WG 8.2 Working Conference on Information Systems and Organizations, IS\&O 2016. Dublin, Ireland, December 9-10, 2016. Springer. doi: https://doi.org/10.1007/978-3-319-49733-4_3

Gibbs, R.W., \& Cameron, L. (2008). The Social-Cognitive Dynamics of Metaphor Performance. Cognitive Systems Research, 9(1-2), 64-75. doi: https://doi.org/10.1016/j.cogsys.2007.06.008

Goldkuhl, G. (2013). The IT Artefact: An Ensemble of the Social and the Technical? - A RejoinDer. Systems, Signs \& Actions, 7(1), 90-99.

Harris, R. (1996). Signs, Language, and Communication: Integrational and Segregational Approaches. London: Routledge.

Hassan, N. R. (2016). Editorial: A Brief History of the Material in Sociomateriality. ACM SIGMIS Database: the DATABASE for Advances in Information Systems, 47(4), 10-22. doi: https://doi.org/10.1145/3025099.3025101

Israel, J. (1979). The Language of Dialectics and the Dialectics of Language. New York: Humanities Press.

Jones, M. (2014). A Matter of Life and Death: Exploring Conceptualizations of Sociomateriality in the Context of Critical Care. MIS Quarterly, 38(3), 895925. doi: https://doi.org/10.25300/MISQ/2014/38.3.12

Kotik-Friedgut, B. (2006). Development of the Lurian Approach: A Cultural Neurolinguistic Perspective. Neuropsychology Review, 16(1), 43-52. doi: https://doi.org/10.1007/s11065006-9003-9

Latour, B. (2009). A Cautious Prometheus? A Few Steps toward a Philosophy of Design (with Special Attention to Peter Sloterdijk). In Fiona Hackne, Jonathn Glynne and Viv Minto (Editors) Proceedings of the 2008 Annual International Conference of the Design History Society - Falmouth, 3-6 September 2009 (pp. 2-10). Universal Publishers.

Leonardi, P. M. (2011). When Flexible Routines Meet Flexible Technologies: Affordance, Constraint, and the Imbrication of Human and Material Agencies. MIS Quarterly, 35(1), 147-167. doi: https://doi.org/10.2307/23043493 
Leonardi, P. (2013). Theoretical Foundations for the Study of Sociomateriality. Information and Organization, 23(2), 59-76. doi: https://doi.org/10.1016/j.infoandorg.2013.02.002

Levins, R., \& Lewontin, RC. (1985). The Dialectical Biologist. Cambridge, Mass: Harvard University Press.

Love, N. (2004). Cognition and the Language Myth. Language Sciences, 26(6), 525-544. doi: https://doi.org/10.1016/j.langsci.2004.09.003

Orlikowski, W. J., \& Scott, S. V. (2008). Sociomateriality: Challenging the Separation of Technology, Work and Organization. The Academy of Management Annals, 2(1), 433-474. doi: https://doi.org/10.1080/19416520802211644

Paul, R. (2010). Loose Change. European Journal of Information Systems, 19, 379-381. doi: https://doi.org/10.1057/ejis.2010.40

Toomela, A. (2014). There Can Be No Cultural-Historical Psychology Without Neuropsychology. And Vice Versa. In A. Yasnitsky, R. van der Veer \& M. Ferrari (Eds.), The Cambridge Hand-book of Cultural-Historical Psychology (pp. 315-349). Cambridge: Cambridge University Press. doi: https://doi.org/10.1017/CBO9781139028097.019

Zinchenko, V. (1996). Developing Activity Theory: The Zone of Proximal Development and Beyond. In B. Nardi (Ed.) Context and Consciousness, Activity Theory and Human-Computer Interaction (pp. 283-324). Cambridge, Massachusetts: MIT Press

Copyright: (C) 2018 Taxén. This is an open-access article distributed under the terms of the Creative Commons Attribution-NonCommercial 3.0 Australia License, which permits noncommercial use, distribution, and reproduction in any medium, provided the original author and AJIS are credited.

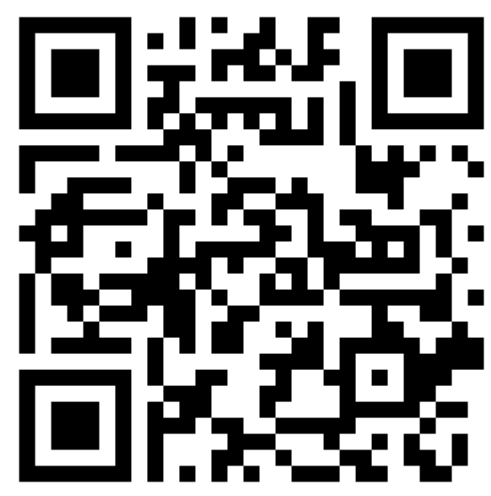

